\title{
Erratum to: Diffusion tensor imaging (DTI) in the detection of white matter lesions in patients with mild cognitive impairment (MCI)
}

Dimitra Sali $\cdot$ D. A. Verganelakis $\cdot$ E. Gotsis $\cdot$ P. Toulas $\cdot$ J. Papatriantafillou

C. Karageorgiou $\cdot$ T. Thomaides $\cdot$ E. Z. Kapsalaki · G. Hadjigeorgiou •

A. Papadimitriou

Published online: 25 June 2013

(C) Belgian Neurological Society 2013

\section{Erratum to: Acta Neurol Belg}

DOI 10.1007/s13760-013-0197-3

In the published original article, the first name and family name of the first author are inverted (Sali is the surname).

The correct name is:

Dimitra Sali

The online version of the original article can be found under doi:10.1007/s13760-013-0197-3.

D. Sali $(\bowtie)$

Euroclinic Athens, Pontou 24 Drosia Attikis,

14572 Athens, Greece

e-mail: dimitrasali@gmail.com

D. A. Verganelakis · E. Gotsis · P. Toulas

Euromedica-Encephalos, Athens, Greece

J. Papatriantafillou · C. Karageorgiou

General Hospital of Athens, Athens, Greece

T. Thomaides

Red Cross Hospital of Athens, Athens, Greece

E. Z. Kapsalaki - G. Hadjigeorgiou - A. Papadimitriou Department of Neurology, University Hospital of Larissa,

Medical School, University of Thessaly, Biopolis, Greece 